\title{
Pancreatic Macrocystic Serous Cystadenoma
}

National Cancer Institute

\section{Source}

National Cancer Institute. Pancreatic Macrocystic Serous Cystadenoma. NCI Thesaurus.

Code C95471.

A benign, non-metastasizing epithelial neoplasm arising from the exocrine pancreas. It is characterized by the presence of a few large cysts and is composed of glycogen-rich epithelial cells which produce a watery fluid. 